\title{
O PROCESSO FORMATIVO DE ESTUDANTES DE DIREITO DIANTE DA TEMÁTICA VIOLÊNCIA CONTRA AS MULHERES
}

\section{THE FORMATIVE PROCESS OF LAW STUDENTS FACING THE THEME VIOLENCE AGAINST WOMEN}

\section{EL PROCESO FORMATIVO DE LOS ESDUDIANTES DE DERECHO ANTE LA VIOLENCIA CONTRA LAS MUJERES}

\author{
Ricardo Gabriel de Araújo ${ }^{1}$ \\ Marcos Vinicius Francisco ${ }^{2}$ \\ Cinthia de Sousa Noguchi ${ }^{3}$
}

\begin{abstract}
Resumo: Neste artigo ${ }^{4}$ assumiu-se como objetivo problematizar o processo de formação de estudantes do curso de Direito, de uma universidade privada, no interior do estado de São Paulo, acerca das discussões sobre a violência contra as mulheres. Participaram da pesquisa de abordagem qualitativa, estudantes ingressantes e concluintes do curso. Os dados foram coletados por meio da aplicação de um questionário e da realização de grupo focal, a partir da exibição do filme "Vidas Partidas". Constatou-se que em momento algum de sua formação os/as estudantes iniciantes presenciaram discussões sobre o processo histórico da violência contra as mulheres, em consonância com os estudos de gênero. Dentre os/as concluintes, sua presença foi mencionada de maneira pontual e técnica por meio da Lei Maria da Penha.
\end{abstract}

Palavras-chave: Lei Maria da Penha. Violência contra as mulheres. Direito. Estudantes.

\footnotetext{
Abstract: This study aimed to discuss the process of training students of law students, from a private university in the interior of the state of São Paulo, about the discussions on violence against women. Participated in the research of qualitative approach, students entering and finishing the course. Data were collected by applying a questionnaire and conducting a focus group from the screening of the movie "Lives Broken". It was found that at no time during their formation did the beginning students

${ }^{1}$ Universidade do Oeste Paulista. Presidente Prudente, São Paulo, Brasil.

${ }^{2}$ Universidade do Oeste Paulista. Presidente Prudente, São Paulo, Brasil./ Universidade Estadual de Maringá. Ivaiporã, Paraná, Brasil.

${ }^{3}$ Universidade do Oeste Paulista. Presidente Prudente, São Paulo, Brasil.

${ }^{4}$ Recorte de pesquisa em nível de mestrado, defendida junto ao Programa de Pós-Graduação em Educação da Universidade do Oeste Paulista.
} 
witness discussions about the historical process of violence against women, in line with gender studies. Among the graduating students, their presence was mentioned in a timely and technical manner through the Maria da Penha Law.

Keywords: Maria da Pena Law. Violence against women. Law. Students.

Resumen: En este artículo, el objetivo fue problematizar el proceso de capacitación de estudiantes en el curso de Derecho, en una universidad privada, en el interior del estado de São Paulo, sobre discusiones sobre violencia contra las mujeres. Los participantes de la investigación con enfoque qualitativo fueran los estudiantes de primer año y los concluyentes. Los datos se recopilaron mediante la aplicación de un cuestionario y la realización de un grupo focal, basado en la proyección de la película "Vidas Partidas". Se descubrió que en ningún momento de su educación los estudiantes principiantes presenciaron discusiones sobre el proceso histórico de violencia contra las mujeres, en línea con los estudios de género. Entre los graduados, su presencia fue mencionada de manera puntual y técnica a través de la Ley Maria da Penha.

Palabras clave: Ley Maria da Penha. Violencia contra la mujer. Derecho Estudiantes.

\section{INTRODUÇÃO}

Nas últimas décadas intensificaram-se os estudos e impactos das diferentes manifestações de violência em diferentes grupos sociais. Diversos/as autores/as abordam a temática na condição de uma produção que estabelece relações de poder entre os sujeitos (CHAUÍ, 1998; NARVAZ; KOLLER, 2006; OLIVEIRA; LIMA; ARANA, 2017). Aponta Chauí (1998, p. 1), a “[...] violência é um ato de brutalidade, sevícia e abuso físico e/ou psíquico contra alguém e caracteriza relações intersubjetivas e sociais definidas pela opressão, intimidação, pelo medo e pelo terror". É preciso compreender que, culturalmente, são estabelecidas e perpetuadas diversas formas de desigualdades, hierarquias contra determinados grupos, dentre estes as mulheres.

Considerando os estudos de Lima, Souza e Silva (2017), a violência doméstica ainda é realidade presente nos lares de muitas mulheres, locais onde são vítimas de agressões físicas, sexuais, morais, psicológicas ou patrimoniais. Parte-se do princípio de que a violência de gênero, em especial, a violência contra as mulheres adquiriu visibilidade no cenário nacional e acadêmico desde a década de 1980, ao se firmar como uma das áreas que motivou os estudos feministas no Brasil (MORAES; RIBEIRO, 2012; MORAIS; CARVALHO, 2015; OLIVEIRA; LIMA; ARANA, 2017). Gomes e Diniz (2008) complementam que foi por meio dos apelos e denúncias do movimento feminista que a violência contra as mulheres ganhou visibilidade pública. 
Ao considerar que os homens (maridos, companheiros, irmãos, pais) são, na maioria das vezes, os principais agressores das mulheres, pode-se dizer que a violência contra as mulheres "[...] é também uma forma de violência de gênero" (NARVAZ; KOLLER, 2006, p. 8). Compreende-se, a partir de Scott (1989), o conceito de gênero como uma construção social. O gênero se torna uma maneira de indicar a criação inteiramente social das ideias sobre os papéis próprios aos homens e às mulheres. É uma maneira de se referir às origens, exclusivamente sociais, das identidades subjetivas dos sujeitos.

Nessa perspectiva, para Gomes et al. (2012a) e Echeverria, Oliveira e Erthal (2017), a violência contra as mulheres vai muito além da dimensão física, ao abarcar, também, as agressões psicológicas, com reflexo na liberdade de escolhas. As investigações sinalizam que os próprios lares se constituem como os locais onde as mulheres mais sofrem formas de violência, sobretudo por seus parceiros (GOMES et al., 2012a; ECHEVERRIA; OLIVEIRA; ERTHAL, 2017; OLIVEIRA; LIMA; ARANA, 2017). Durante muito tempo esse processo se traduzia como um dos acontecimentos típicos da vida conjugal. Destaca-se também que "[...] neste espaço (privado) os demais membros da sociedade e o Estado aparentemente não destinavam grandes preocupações" (OLIVEIRA; LIMA; ARANA, 2017, p. 206).

Lima, Souza e Silva (2017, p. 196) complementam, “[...] a violência doméstica é um dos tipos de violência mais perversos e corriqueiros, pois o agressor se aproveita do vínculo afetivo e de morar com a vítima para violentá-la". Numa perspectiva patriarcal, o homem exerce um controle sobre a mulher, ao acreditar que suas regras são soberanas, devendo as decisões majoritárias serem tomadas por ele. Essa lógica explicita o controle exercido sobre as mulheres, pari passu são visualizadas como meros objetos (GOMES; DINIZ, 2008; GARCIA, 2016).

A violência intrafamiliar constitui-se como um problema de saúde pública (SOUZA et al., 2009). Garbin et al. (2016, p. 183) ponderam que, em 2011, por exemplo, “o custo da violência no país foi estimado em R\$ 207,2 bilhões, 5\% do PIB (Produto Interno Bruto) nacional”. Em oposição, a prevenção é a única forma de diminuir os índices de violência, assim como obter uma economia significativa. Na mesma linha de análises, de acordo com o "cálculo do Banco Interamericano de Desenvolvimento (BID), para cada dólar gasto em prevenção, economizam-se de seis a sete vezes os recursos investidos em repressão policial à violência" (GARBIN et al., 2016, p. 183).

As mulheres vítimas de violência doméstica quando procuram entidades que poderão lhe conferir ajuda e garantia de uma vida sem agressões, mantêm contato, por exemplo, com profissionais do Direito, seja em delegacias especializadas ou ligadas ao Poder Judiciário 
(advogados/as, promotores/as e juízes/as). Os/As profissionais da área jurídica que irão realizar os atendimentos necessitam compreender o processo histórico dessa forma de agressão, bem como terem se apropriado dos fundamentos que subsidiaram a Lei Maria da Penha - $\mathrm{n}$ 11.340/2006 - que coíbe essa forma de violência (BRASIL, 2006).

Torna-se fundamental o preparo adequado dos/as futuros/as profissionais que atuarão nas áreas de atendimento primário, a fim de que tenham um conhecimento mais denso sobre o tema violência, para que sua atuação não gere novas violências (GOMES et al., 2012b). O curso em Direito, foco desta investigação, deve reconstruir o papel social do/a profissional jurídico/a, a fim de que o/a estudante bacharel assuma o seu papel e se posicione contra toda e qualquer manifestação de violência (SOUZA et al., 2009).

Em muitos cursos, o/a bacharel em Direito recebe apenas uma formação técnica e pragmática, a qual não prioriza a análise dos fenômenos, a exemplo da violência, como problemática social (MAROCCO, 2011). Diante de tal premissa, os seguintes questionamentos direcionaram este estudo: os/as profissionais da área jurídica, durante seu processo de formação inicial, em algum momento, de sua formação acadêmica, participaram de discussões sobre o processo histórico de produção da violência e de desigualdades contra as mulheres? Tiveram contato com a Lei no 11.340/2006 (BRASIL, 2006) e objetivaram sua importância? Apresentar o dispositivo legal supracitado, bem como as discussões sobre violência de gênero e violência contra as mulheres é o suficiente para conscientizar os/as futuros/as profissionais?

Assim, o presente estudo delimitou-se a partir do objetivo geral: problematizar o processo de formação de estudantes do curso de Direito, de uma universidade privada, no interior do estado de São Paulo, acerca das discussões sobre a violência contra as mulheres.

\section{MÉTODO}

Esta investigação foi conduzida a partir da abordagem qualitativa de natureza explicativa. Minayo (2012) ressalta que a pesquisa qualitativa responde a questões muito específicas. Nessa perspectiva são desenvolvidas análises que não podem ser apenas quantificadas, ao priorizar um universo de significados, motivos, aspirações, crenças, valores e atitudes. Complementa-se que a "abordagem qualitativa aprofunda-se no mundo dos significados das ações e relações humanas, um lado não perceptível e não captável em equações, médias e estatísticas" (MINAYO, 2012, p. 622). 


\subsection{LOCAL E PARTICIPANTES}

A pesquisa foi realizada em uma universidade de grande porte do interior do estado de São Paulo. Os/As participantes foram estudantes ingressantes e concluintes, especificamente, matriculados/as no primeiro e último termos do curso de graduação em Direito, ambos do período noturno. Termos de Assentimento e de Consentimento Livre Esclarecido (TCLE) foram entregues aos participantes, bem como aos seus responsáveis, no caso dos/as menores de 18 anos de idade, conforme preceitos da ética em pesquisa com seres humanos.

\subsubsection{Procedimentos de coleta e análise dos dados}

Inicialmente foi utilizado para a coleta de dados um questionário com questões abertas. Vale apontar que o referido contou com três questões que, em linhas gerais, objetivavam saber se os/as estudantes já presenciaram alguma situação de violência contra as mulheres, e qual a tipologia dessa violência, caso a resposta anterior fosse afirmativa; e se as vítimas buscaram algum tipo de apoio. Todos os/as estudantes do 1 을 termo (86) e 10을 termo (61) foram convidados/as a participar da pesquisa, sendo que destes/as: 35 (40,69\%) dos/as ingressantes e 49 (80,32\%) dos/as concluintes apresentaram os Termos de Assentimento e Consentimento Livre Esclarecido (quando necessário para os/as menores de 18 anos). Dessa forma, os dados quantitativos apresentados e analisados na próxima seção referem-se aos/as que apresentaram os referidos documentos.

Após o preenchimento, as respostas foram analisadas, a fim de selecionar por meio de sorteio aleatório os/as oito participantes da segunda etapa. Conforme Gondim (2002), o número adequado para um grupo focal varia entre quatro e dez pessoas. Pondera-se que, grupos grandes coíbem a participação ativa dos/as participantes, já que se almeja que possam expor seus posicionamentos acerca do tema discutido coletivamente.

Foram sorteados/as quatro estudantes do 1으 termo e quatro estudantes do 10을 termo, sendo duas do sexo feminino e dois do sexo masculino, para cada termo. Vale apontar que o sorteio obedeceu aos seguintes critérios, para cada termo e para cada sexo: a seleção de estudantes que presenciaram situações de violência contra as mulheres (02) e que não presenciaram tais ocorrências (02).

A seleção de uma amostra de oito participantes para a próxima etapa deveu-se ao fato de que a referida ocorreu no formato de um grupo focal, o qual aconteceu após a exibição do filme 
brasileiro Vidas Partidas, dirigido por Marcos Schechtman (2016). Todo esse processo teve duração de aproximadamente três horas. As falas produzidas durante o grupo focal foram gravadas e transcritas para o processo de análise dos dados. Nesse sentido, o roteiro para o grupo focal abarcou os seguintes questionamentos: o que identificaram a partir da exibição do filme; o que pensam do que ali foi apresentado; se no curso de Direito o tema em tela foi discutido e de que forma; se antes da universidade já haviam discutido o assunto e em quais espaços; se conheciam a Lei Maria da Penha e onde tiveram contato com a referida; o que era necessário para reduzir os casos de violência de gênero e contra as mulheres.

Os dados obtidos por meio do questionário com questões abertas, bem como os gerados a partir do grupo focal, foram analisados por meio de unidades analíticas que abarcaram os objetivos desta investigação. As duas unidades analíticas abordadas foram as seguintes: "Percepções sobre a violência contra as mulheres" e "A formação inicial em Direito e a violência contra as mulheres e a Lei Maria da Penha".

\section{PERCEPÇÕES SOBRE A VIOLÊNCIA CONTRA AS MULHERES}

O gráfico 1 retrata, a partir do questionário, a quantidade de estudantes que presenciaram algum tipo de violência contra as mulheres. Destaca-se a predominância dos/as estudantes iniciantes $(54,09 \%)$ e dos/as concluintes $(54,00 \%)$ que presenciaram algum tipo de violência contra as mulheres, enquanto que, $45,90 \%$ e $46,00 \%$, respectivamente, dos/as estudantes iniciantes e concluintes apontaram não ter presenciado esse tipo de situação.

Gráfico 1 - Quantidade de alunos/as que presenciaram algum tipo de violência contra as mulheres

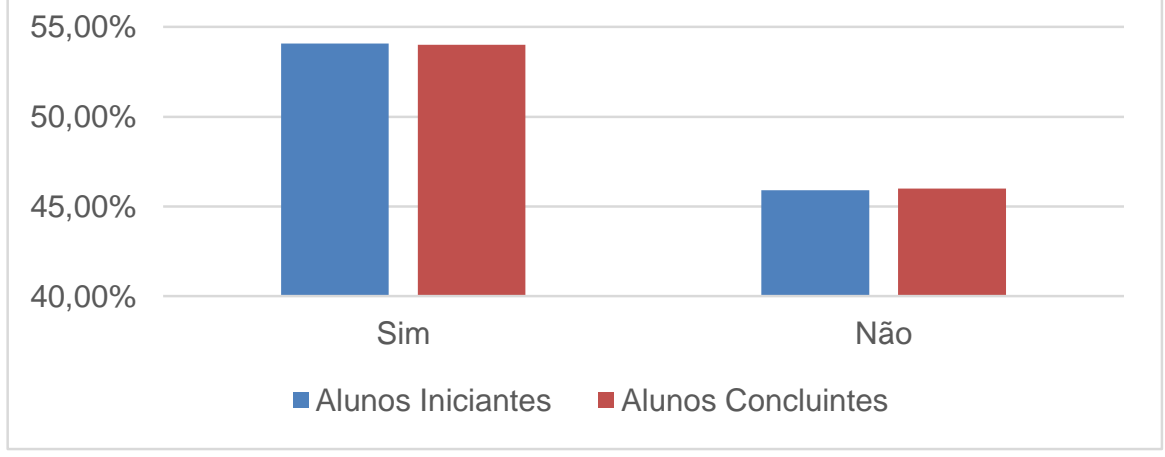

Fonte: Pesquisa de campo (2017-2018).

Estes dados puderam ser aprofundados, após a exibição do filme e, embora uma das participantes do grupo focal tenha enfatizado não ter situações de violência na família, o filme 
oportunizou a visualização do real sofrimento de mulheres submetidas às diferentes formas de violência:

Eu acho que a gente viu e ouviu o que está acontecendo. Não tenho caso de violência na minha família, então eu não consigo ver o dia a dia, mas o filme conseguiu retratar isso, ao mostrar a vida dela e o quanto ela sofreu (Participante 07, concluinte, sexo feminino, Grupo Focal).

Outra participante relatou o sentimento de impotência gerado a partir do filme:

É revoltante, um sentimento de impotência. Um cara completamente machista que acha que não fez nada e se redime pelo que fez. A gente fica impotente com a situação dela. A mulher está com medo do cara, como assim? Eu não sei, mas Graças a Deus eu nunca presenciei ou passei por isso, mas a gente vê que é uma situação de impotência, que a mulher não consegue se defender e naquela época não tinha como se defender legalmente (Participante 01, concluinte, sexo feminino, Grupo Focal).

Tais dados revelam a importância de se garantir espaços de debate nos diferentes níveis de formação, a fim de que as pessoas possam refletir sobre as diferentes formas de violência construídas e reforçadas historicamente e culturalmente. Francisco (2013) reitera o potencial dos filmes, da música, do teatro, da dança, das obras de arte, da literatura e diferentes gêneros textuais, já que além de produzirem recepção estética, são capazes de problematizar a realidade por meio de um trabalho educativo intencional, a fim de que os/as estudantes interpretem a realidade como uma passagem do ser ao dever-ser.

Dos/as estudantes que presenciaram alguma forma de violência, por meio dos questionários foi possível observar que, em vários casos, houve o depoimento de que o agressor estava alcoolizado:

Esposo da minha tia, ingeria bebida alcoólica e se tornava violento, agredia verbalmente e fisicamente ela e sua filha (Participante 01, ingressante, sexo feminino, questionário).

[...] um casal estava viajando e o marido bêbado mandou a esposa trocar o pneu furado e por ela não conseguir, ele bateu nela com a chave (Participante 02, ingressante, sexo feminino, questionário).

Nesse último relato observa-se que o homem se volta contra a mulher pelo fato da mesma não conseguir realizar uma atividade por ele solicitada, aspecto que corrobora com o estudo de Rosa et al. (2008, p. 156), pois “[...] a violência pode ser pensada do ponto de vista de relações de forças expressas enquanto relações de dominação". Em muitos casos, os relacionamentos conjugais são construídos por meio de uma relação assimétrica de poder, nos quais os homens se valem de meios e subterfúgios para controlar suas companheiras (GOMES; DINIZ, 2008; LIMA; SOUZA; SILVA, 
2017). Tal perspectiva foi confirmada pelos dados obtidos por meio do grupo focal, no qual duas participantes relataram a agressão de familiares que fizeram o uso de bebidas alcoólicas, e quando embriagados cometeram agressões contra as mulheres:

Na minha família eu tenho casos, mas é muito psicológico, pois ela não denuncia por medo. Ela tem o apoio de todo mundo da família, a gente não consegue denunciar, pois não temos como provar [...] quando acontece não estamos presente. Ela tem medo, ele ameaça ela, e simplesmente ela nunca denunciou e faz muitos anos que ela está com ele. É casada com ele uma vida inteira, ele sai com outras mulheres na rua pra todo mundo ver e ela não denuncia por medo. Ela não precisa dele financeiramente, a casa é dela, ela tem amparo o suficiente pra viver sozinha, mas é muito psicológico. É medo, ela não consegue e não conseguimos ajuda-la porque não estamos presente quando acontecesse e se falarmos ela vai negar a situação. Ela tem um filho, e quando o filho está presente ele não deixa, ele interfere e não deixa que as agressões aconteçam. Mas quando ele vai trabalhar e ela fica sozinha, o marido dela bebe, volta para casa bêbado e toda vez que ele volta é agressão, acontece isso (Participante 01, ingressante, sexo feminino, Grupo Focal).

Na minha família já teve quatro casos, dois um pouco antes de eu ter certo discernimento e outros dois que eu vi com mais clareza, com uma tia e uma prima, ambas não quiseram prestar queixa. A minha prima tinha sido agredida, pois ela estava com um roxo bem grande no olho e falava que tinha caído e tudo, no entanto, depois começou a ficar bem evidente com marcas no corpo, de agressão mesmo e ela não quis fazer nada. O mesmo aconteceu com a minha tia. Acho legal levantar que nos quatro casos os agressores estavam sob o efeito do álcool no momento da agressão (Participante 02, ingressante, sexo feminino, Grupo Focal).

Para Echeverria, Oliveira e Erthal (2017), o uso do álcool pode ser considerado potencializador para o aparecimento de casos de violência doméstica. Ainda de acordo com as pesquisadoras, para além da dimensão presente na ingestão de bebidas alcoólicas é importante frisar que as mulheres vítimas de agressão tendem a se calar perante as formas de violência sofridas, em seus lares, sobretudo em função da dinâmica patriarcal que impera nesses relacionamentos. É possível observar também que, quando questionados/as sobre as formas de violências presenciadas, em alguns casos, na percepção dos/as participantes houve referências à violência física e verbal, decorrente do uso de bebidas alcóolicas, sendo que as vítimas tentam, por outros meios, afastar seus agressores do uso da bebida:

Agressão verbal e física. Ocorre sempre que o marido volta alcoolizado para casa. Algumas vezes, são controladas pelo filho que intervém na situação, ou por remédios que a vítima coloca escondido na comida do agressor para que ele não beba ou para que durma (Participante 02, ingressante, sexo feminino, questionário).

É importante apontar que, embora tal situação seja nomeada como violência doméstica, também pode ser denominada como violência conjugal, por ocorrer dentro do ambiente doméstico, 
além de ser perpetrada entre parceiros íntimos ou pessoas que possuam um relacionamento próximo, seja afetivo, sexual ou familiar. Nessa perspectiva, Rosa e Falcke (2014) apontam algumas diferenças entre os homens e as mulheres, no que diz respeito à violência dentro do relacionamento. Muitos homens, por exemplo, não consideram como violência a agressão verbal ou física por meio de puxões de cabelo e empurrões (ROSA; FALCKE, 2014).

Conforme Rosa et al. (2008, p. 157), ao ouvir os agressores a fim de compreender sua ótica sobre a violência perpetrada contra as mulheres, alguns apontaram o uso do álcool como um dos motivadores para as situações de desentendimento e agressão. Porém, é importante frisar, o uso do álcool não torna menos grave (atenuante) os casos de violências praticados. $O$ ato da violência não poderá ser desconsiderado, mesmo quando o agressor alegar que estava sob o efeito de álcool, a fim de se livrar de uma possível condenação judicial. Independentemente da presença ou ausência de bebida, a violência cometida fere a dignidade da vítima.

A partir do questionário, no gráfico 2 são apresentados os locais onde os/as participantes deste estudo presenciaram algum tipo de violência contra as mulheres:

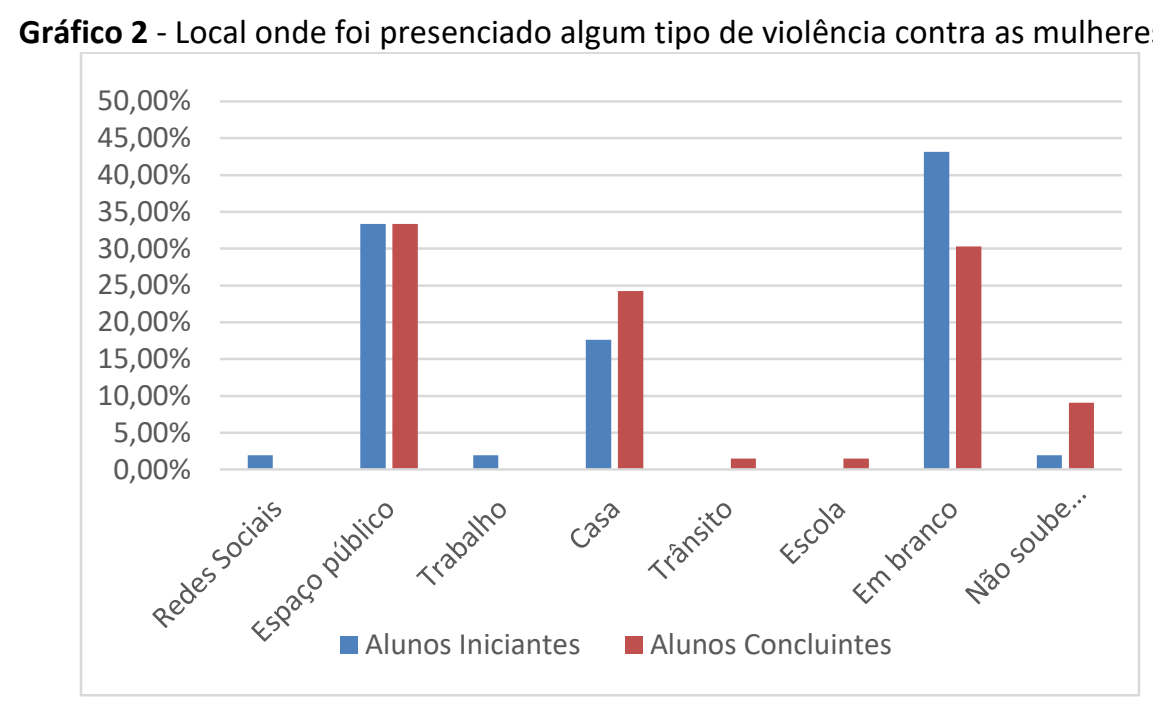

Fonte: Pesquisa de campo (2017-2018).

Percebe-se que os locais onde mais presenciaram situações de violência contra as mulheres foram em espaços públicos, o que justifica a equivalência dos percentuais apresentados (33,33\%) pelos/as estudantes iniciantes e concluintes. Para além desse espaço, destacaram-se os/as que presenciaram dentro de casa, sendo $17,64 \%$ para os/as estudantes iniciantes e $24,24 \%$ para os/as concluintes. 
Sobre as agressões serem cometidas na presença de crianças, sobretudo nos espaços públicos ou dentro de casa, Santos e Moré (2011) denunciam a transgeracionalidade da agressão. Há casos, nos quais os/as filhos/as "[...] são vítimas diretas das ameaças e agressões verbais e físicas desferidas pelos agressores" (SANTOS; MORÉ, 2011, p. 230). Apontam ainda que, a atitude do agressor pode resultar em sequelas psicológicas e comportamentais para aqueles/as que presenciaram situações de violência.

Vale ainda reprisar as constatações de D'Oliveira et al. (2009, p. 301), as quais vão na direção de que "[...] testemunhar violência contra a mãe e sofrer violência física cometida pelos pais aumentam o risco de sofrer violência por parceiro íntimo na vida adulta". A pesquisa que analisou a intervenção psicoterapêutica com agressor conjugal, desenvolvida por Padovani e Williams (2002, p. 15), revelou que um dos agressores entrevistados "[...] mencionou que desde criança fora 'educado' com base em castigos corporais e que 'aprender era sinônimo de apanhar'”.

Quanto aos tipos de violências presenciadas pelos/as estudantes, por meio do questionário, foram destacadas a violência física, a violência verbal e, inclusive, a violência psicológica, como observado no gráfico a seguir:

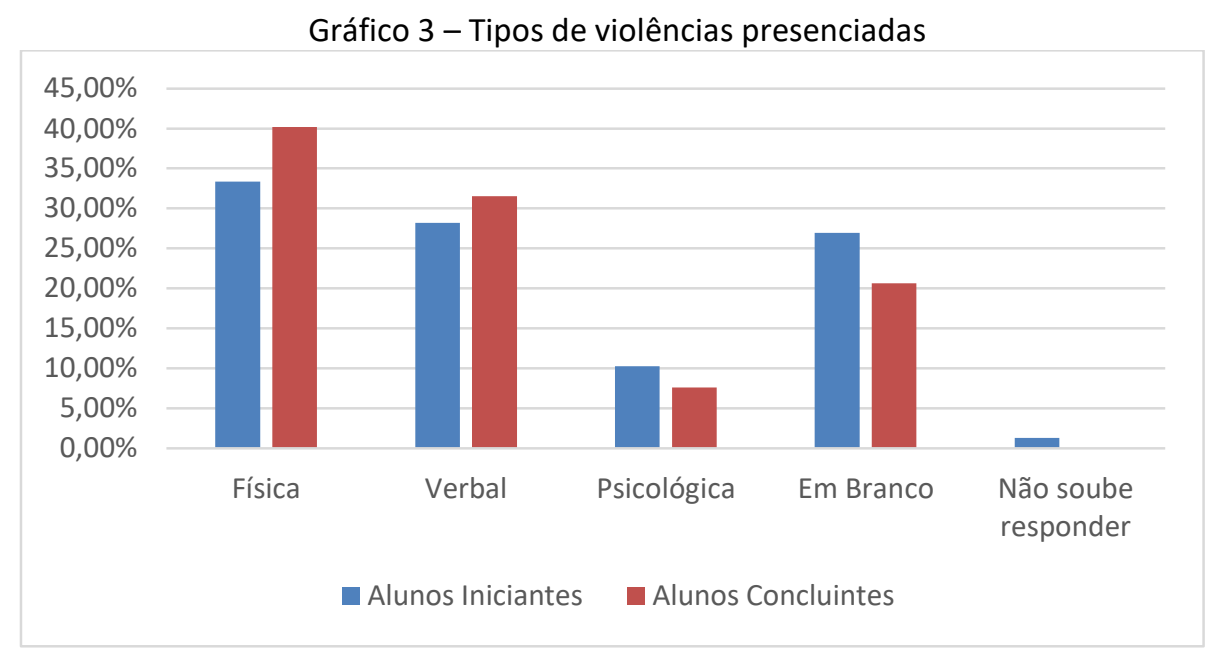

Fonte: Pesquisa de campo (2017-2018).

Sobre a violência física, pode-se descrever que ela "[...] ocorre quando uma pessoa, que está em posição de poder em relação à outra pessoa, causa ou tenta causar dano não acidental por meio de força física" (NARVAZ; KOLLER, 2006, p. 8). A violência verbal se caracteriza por meio de ataques expressos em xingamentos e ofensas verbais. Enquanto que a violência psicológica se expressa nas situações de opressão e ameaças que culminam na tortura psicológica das vítimas. Os trechos abaixo exemplificam algumas formas de violências presenciadas pelos/as participantes da pesquisa: 
Primeiro, começou com uma discussão, aí foi se acalorando, era discussão de casal, o marido da minha vizinha estava bem nervoso, aí só pelo fato dela o mandar baixar a bola, ele perdeu a cabeça a segurou pelo braço e a chacoalhou e a empurrou. Ela pra se defender levantou e o empurrou, em seguida, ele deu um tapa nela, mas nós ouvimos e corremos separar (nós minha família) (Participante 18, ingressante, sexo feminino, questionário).

Sim, no meu ciclo social convivi com um relacionamento abusivo entre duas mulheres. De que forma era essa violência? De várias formas, desde privação da liberdade e autonomia, até traições justificadas por ciúmes excessivo, chegando a violência física (Participante 09, concluinte, sexo masculino, questionário).

Ainda sobre a violência contra as mulheres, no gráfico 4, a partir das respostas questionouse, a/s vítima/s buscou/buscaram por apoio diante da agressão experienciada?

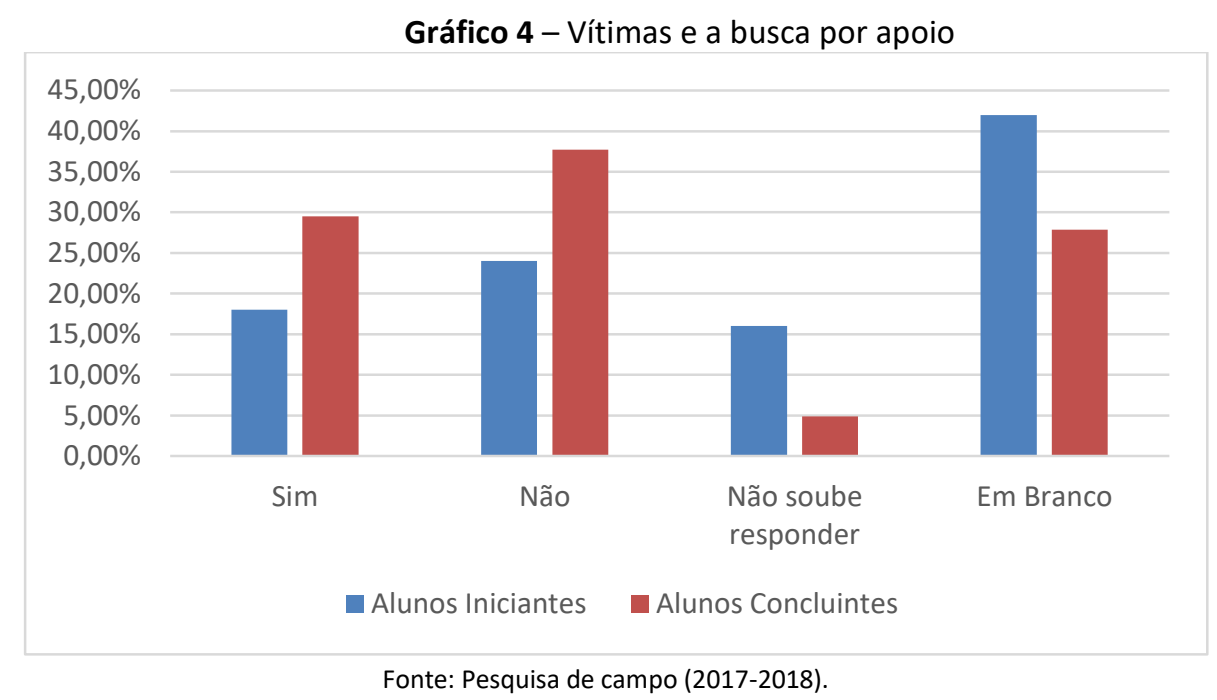

Chama atenção o fato de que, parcela expressiva dos/as estudantes concluintes $(37,70 \%)$ mencionou que as vítimas não buscaram nenhum tipo de apoio diante da violência vivenciada. Da mesma forma, tais dados foram apontados por $24 \%$ dos/as estudantes iniciantes. Apenas $24 \%$ dos/as estudantes iniciantes destacaram que as vítimas buscaram auxílio, situação mencionada por $29,50 \%$ dos/as estudantes concluintes. Abaixo, são apresentados alguns exemplos que coadunam com tais dados:

Pelos relatos que ouvi, nenhuma delas buscou algum tipo de apoio, preferiram não correr o risco de o agressor saber e tentar uma nova agressão (Participante 03, ingressante, sexo masculino, questionário).

De início não, a vergonha foi fator determinante; depois o medo. Mas por fim, busquei apoio no judiciário (Participante 01, concluinte, sexo feminino, questionário). 
A vítima não buscou apoio em razão do agressor ser seu marido, e também não conversei a respeito do assunto com outras pessoas (Participante 12, concluinte, sexo feminino, questionário).

A vítima prefere não denunciar e aconselha as pessoas que sabem da situação a não denunciarem também, pois tem medo de algo mais grave ocorra, pois já sofreu ameaça (Participante 02, ingressante, sexo feminino, questionário).

Às vezes, as vítimas de violências realizam registros de ocorrência, mas reatam o relacionamento com o agressor, a exemplo do seguinte relato:

Eu conheço um caso em que eu convivi com uma família por um período, nada familiar meu, apenas conhecidos, e essa pessoa era muito agredida, ela não podia conversar com a família senão ele a agredia, além da mãe e a irmã. Então, ela não podia conversar com a família dela, ficava afastada. Assim, era agredida várias vezes, ia para a polícia e como acontecia no filme, ele vinha ficava com moleza e ela voltava para ele. Agredia de novo, ia para a polícia, pedia medida protetiva e eles voltavam [...], em uma semana ela estava de volta com ele. Então ela se submetia muito a isso (Participante 07 , concluinte, sexo feminino, Grupo Focal).

Tais dados coadunam com os achados de Echeverria, Oliveira e Erthal (2017), já que algumas mulheres vítimas de violências perdoam seus companheiros na expectativa de que eles mudem seus hábitos machistas e comportamentos violentos. Somente em casos de contato com violência muito traumática é que algumas mulheres procuram por ajuda.

É importante que não se reproduzam interpretações simplistas que culpabilizam as mulheres por não conseguirem efetuar as denúncias, por meio de discursos, tais como o apresentado pela participante 07 (concluinte). O fenômeno da violência contra as mulheres precisa ser interpretado diante de suas múltiplas determinações, quais sejam, por exemplo, as questões de gênero historicamente construídas, os valores culturais e religiosos, o medo, a fragilidade emocional das vítimas, dentre tantos outros.

Para Narvaz e Koller (2006), as vítimas diante de situações de violência crônica, comumente, apresentam um estado alterado de consciência, ao culminar com a submissão passiva diante de manipulações praticadas pelos perpetradores da violência. Podendo ainda, “[...] concomitantemente, experimentarem vergonha, culpa e baixa autoestima por viverem esse tipo de situação, além do medo de ficarem sozinhas" (SANTOS; MORÉ, 2011, p. 222).

No gráfico a seguir, apresentam-se os tipos de apoio buscados pelas vítimas diante da violência sofrida: 


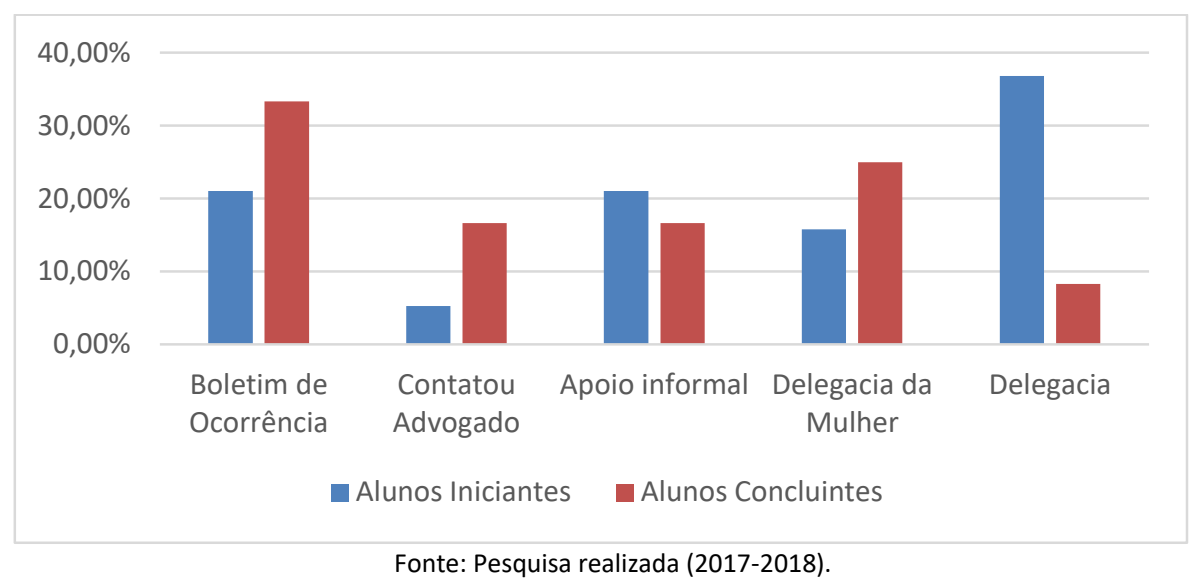

Embora o gráfico tenha sido construído a partir das repostas dadas pelos/as participantes, interpreta-se que o boletim de ocorrência (B.O), a delegacia da mulher e a delegacia geral podem ser considerados como dimensões complementares e as mais expressivas nesta investigação. Os outros dados obtidos envolvem o apoio informal, no qual foi constatado pelos/as estudantes ingressantes (21,05\%) e pelos/as concluintes (16,66\%), ou seja, quando as vítimas buscam apenas o amparo familiar, de amigos, entre outros. Complementa-se que a procura por um/a advogado/a foi indicado por apenas 5,26\% dos/as estudantes iniciantes e 16,66\% dos/as estudantes concluintes.

Constatou-se, ainda, por meio do grupo focal, situação na qual a vítima de agressão realizou a formalização da notificação da violência sofrida, a exemplo da confecção de um B.O perante a autoridade policial, entretanto, não obteve sucesso. Tais dados levam a problematizar que outras agressões poderiam ocorrer com essa vítima, como sinalizado na sequência:

Agora nos casos de ter 100, 200 ou 300 metros se aproximar ou não, ai é uma questão de Estado. Se o cara tiver que ir lá e matar, ele mata, mas são casos e casos. (Participante 06, concluinte, sexo masculino, Grupo Focal).

Desse modo, é necessário ainda voltar os olhares para a adequada formação do/a futuro/a profissional jurídico/a, inclusive para que não sejam naturalizadas as situações de violência contra as mulheres, em especial, com as que tiverem contato futuramente. Às vezes, falta sensibilidade por parte dos/as profissionais que efetuam o atendimento às vítimas (BOULOS; ROSENTHAL; DUARTE, 2016), embora se deva reconhecer que um avanço foi obtido com a criação das Delegacias de Defesa da Mulher (LEMOS, 2008; BRABO, 2015).

Na próxima unidade analítica, por exemplo, será possível observar que os/as participantes da pesquisa demonstraram uma carência de debates sobre os temas da violência de gênero e contra as mulheres, ao desconhecerem, inclusive, a construção histórica e articulação das temáticas. Tal problema é agravado quando algumas mulheres, vítimas de agressões, ao buscarem ajuda em 
unidades de saúde, não são atendidas da forma correta (BOULOS; ROSENTHAL; DUARTE, 2016), aspectos evidenciados por uma das participantes no grupo focal:

Eu trabalho na saúde pública e já peguei vários casos de mulheres agredidas e a gente não pode fazer nada se ela não fizer. Nós instruímos, mas mesmo sem elas denunciarem, outras pessoas poderiam fazer e ser válido, porque a gente vê, orienta, mas a pessoa fala não. Ficamos de mãos atadas, pois se elas não denunciam nada acontece (Participante 04, ingressante, sexo Feminino, Grupo Focal).

Em alguns casos, por exemplo, a violência poderá ser descoberta após um atendimento médico hospitalar, por meio do qual a vítima de agressão ao comparecer perante um hospital ou uma unidade de saúde trará indícios de agressão doméstica. O/A profissional de saúde ao identificar, ainda que de forma bem velada, se tratar de uma vítima de agressão poderá encaminhar imediatamente aos órgãos competentes, seja delegacia da mulher ou qualquer delegacia da polícia civil. Todavia, de acordo com Boulos, Rosenthal e Duarte (2016), ainda impera um despreparo dos/as profissionais da saúde que, muitas vezes, não sabem ou não direcionam sua escuta e seu olhar para diagnosticar uma situação de violência.

\subsection{A FORMAÇÃO INICIAL EM DIREITO E A VIOLÊNCIA CONTRA AS MULHERES E A LEI MARIA DA PENHA}

Na realização do grupo focal, observaram-se alguns pontos de grande relevância para a formação jurídica dos/as estudantes do curso de Direito. Quando foram indagados/as se antes do ingresso na Universidade já haviam discutido os temas da violência de gênero e contra as mulheres em algum espaço, somente dois participantes acenaram positivamente. Segue suas falas para exemplificação:

Na minha família já teve quatro casos, dois, um pouco antes de eu ter certo discernimento e outros dois que eu vi com mais clareza, com uma tia e uma prima, ambas não quiseram prestar queixa [...]. (Participante 01, ingressante, sexo masculino, Grupo Focal).

Através da Mídia (Participante 03, ingressante, sexo feminino, Grupo Focal).

É possível observar que, no primeiro relato o participante ingressante somente teve contato com a Lei pelo motivo de ter vivenciado uma espécie de violência dentro de sua família. A outra participante, do grupo focal, também declarou que antes de seu ingresso na universidade, somente teve contato com o dispositivo legal por meio da mídia. Chama atenção o quanto a temática está distante da educação escolar, sobretudo na educação básica. 
Assim, o/a bacharel em Direito após sua graduação atuará em casos de relevância social, ou seja, sua profissão possui grande impacto social (MAROCCO, 2011). Entretanto, para que seja possível o/a operador/a do direito atuar de forma precisa, existe a necessidade de uma formação adequada, na qual a universidade se torna responsável por ser o berço de discussões e amplos debates sobre diversos temas.

No grupo focal, identificaram-se algumas fragilidades na formação inicial dos/as estudantes. Quando indagados/as se, em algum momento da formação acadêmica, participaram de discussões sobre a temática da violência contra as mulheres, em consonância com os estudos de gênero, os/as iniciantes foram unânimes ao afirmar que não. Apenas duas falas de concluintes revelaram um contato pontual, por meio da Lei Maria da Penha em uma das disciplinas do curso, mas de maneira muito técnica. Nessa conjuntura, fica explícito que não houve a possibilidade desses/as estudantes apropriarem-se do tema.

Tais aspectos revelam carências na formação inicial dos/as futuros/as operadores/as do Direito, que poderão os/as impedir de identificar, por exemplo, os fatos históricos que constituíram o patriarcalismo, o machismo, bem como a negação das discussões de gênero. Infelizmente, impera uma formação técnica, por meio da qual os/as estudantes têm contato, apenas, com a lei, de tal forma como deverão usá-la perante a autoridade policial e poder judiciário. A apresentação da Lei no. 11.340/2006 (Lei Maria da Penha), por si só, em sala de aula, não é suficiente para se compreender as complexas discussões sobre as violências de gênero, em especial as praticadas contra as mulheres.

Ao não se identificar espaços para discussões, debates e fóruns sobre a violência contra as mulheres diante de sua construção social e histórica, poderão perpetuar interpretações simplistas que não corroborarão com uma análise mais dialética do processo. Acrescido a isso, terão dificuldades de identificar os motivos que, culturalmente, conduzem os agressores a adotarem determinadas atitudes:

Eu só fiquei um pouco confusa por não saber identificar porque isso ocorre, porque um homem agride uma mulher? O que ele pensa? O que o motiva? Eu não sei se é algo psicológico, formação de caráter, se vem de infância, eu não consigo identificar (Participante 03, ingressante, sexo feminino, Grupo Focal).

Para além dos aspectos anteriormente destacados, é importante salientar que o conhecimento superficial sobre o tema coaduna com a reprodução de preconceitos que culpabilizam as vítimas pela não efetivação da denúncia, bem como que coloca em xeque a veracidade das denúncias de violências sofridas pelas mulheres. $O$ trecho abaixo retrata bem essa 
situação. Entretanto, pondera-se, caso uma denúncia seja falsa, sem fundamentos, ela não irá se sustentar, mas argumentos como o apresentado pela Participante 05 (concluinte) apenas naturalizam o que está perpetuado:

Fui para o Hotel com eles e em uma semana ela estava de volta com ele. Então ela se submetia muito a isso, por isso eu fico meio assim, com a lei, pois como alguém já disse, vão acreditar no que as pessoas vão dizer, tendo o lado contrário, também, da mulher em fazer a falsa denúncia, onde ela diz que foi agredida quando ela não foi. [...] Às vezes, o cara vai segurar ela ou qualquer outra coisa e acaba machucando e homem segura forte. Então eu penso nas outras pessoas denunciando, pois vai ter muita denuncia falsa, o que já se tem. Isso não tira o fato dos casos que tenha violência, mas em muitos casos eu vejo que a mulher se submete muito a isso, eu não tive experiência, mas se acontecer a primeira vez será pra nunca mais. (Participante 05, concluinte, sexo feminino, Grupo Focal).

Uma participante do grupo focal suscitou a necessidade de compreensão do agressor, com o objetivo de entender os motivos que o levam a perpetrar tais atos de violência:

Eu me sinto sem saber o que fazer ou como poder ajudar, porque eu acho que não apenas essas mulheres precisam de ajuda, mas essas pessoas que agridem também precisam. Acho que pode ser algo controlado e/ou evitado, no qual poderiam ter uma ajuda psicológica (Participante 03, ingressante, sexo feminino, Grupo Focal).

Torna-se necessário o entendimento de que por tratar-se a violência de violação contra os direitos humanos, o principal papel da academia seria o de preparar os/as futuros/as bacharéis para uma formação com bases históricas, ao permitir o contato com discussões sobre a origem da construção social da violência contra as mulheres, o que culminará com uma compreensão crítica e situada diante da temática. A investigação de Silva et al. $(2016$, p. 4) coaduna na perspectiva de que se "a violência contra a mulher é uma violação dos direitos humanos", faz-se "necessário empenho de toda a sociedade para erradicar as causas e eliminar as consequências dessa violação".

Com base no relato acima, defende-se que o Estado precisa assumir a implantação de políticas educativas que promovam discussões sobre a violência contra as mulheres, assim como sobre a temática de gênero, com os/as estudantes da graduação em Direito, bem como das demais áreas do conhecimento. Trata-se de assuntos indispensáveis para uma melhor formação acadêmica e humana. Nessa perspectiva, Morais e Carvalho (2015) salientam sobre a necessidade de se trazer os estudos de gênero para o interior das universidades, a fim de institucionalizá-los além das importantes contribuições das militantes do movimento feminista.

As discussões associadas à categoria gênero, no ensino superior, não deverão aparecer nessa etapa de formação como novidade, mas como um movimento contínuo estabelecido desde a educação básica (CAETANO; LIMA; CASTRO, 2019; CARDOSO; ZIMMERMANN, 2019). Daí a 
importância de garantir sua presença nas políticas curriculares nacionais, sobretudo em documentos oficiais (CARDOSO; ZIMMERMANN, 2019; RIOS; VIEIRA, 2020).

Recentemente o CNJ - Conselho Nacional de Justiça, por meio de sua Ministra Cármen Lúcia, editou a Portaria no 15 de 8 de março de 2017, que aponta a “[...] necessidade de adequação da atuação do Poder Judiciário para a consideração da perspectiva de gênero na prestação jurisdicional" (BRASIL, 2017, p.1).

Infere-se, ainda, a alteração pontual de uma matriz curricular, do curso de Direito, por meio da inclusão de uma disciplina que aborde as temáticas centrais deste artigo não é suficiente para garantir uma formação e futura atuação diferenciadas. Tais discussões precisam ser incorporadas na dinâmica do Projeto Político Pedagógico de um curso, ao perpassar toda a formação em Direito.

\section{CONSIDERAÇÕES FINAIS}

Durante a execução desta pesquisa, por meio da aplicação dos questionários ou até mesmo do grupo focal, identificou-se que a maioria dos/as estudantes, ingressantes ou concluintes, teve contato ou conhece alguma mulher que sofreu violência. No que tange aos tipos de violências presenciadas, os/as participantes mencionaram a física, a verbal e a psicológica. Com relação aos locais onde mais presenciaram situações de violência, foram apontados os espaços públicos, bem como nos próprios lares das vítimas.

Os dados obtidos via aplicação do questionário ainda revelaram, parcela expressiva dos/as estudantes iniciantes e concluintes sinalizou que muitas vítimas não buscam nenhum tipo de apoio diante da violência experienciada, a exemplo do medo de sofrer novas agressões. Nessa perspectiva, as Delegacias da Mulher, os Postos de Saúde ou outros órgãos de atendimento possuem grande importância social em casos de violência contra as mulheres, sobretudo na identificação e notificação das agressões, de tal modo que as medidas cabíveis de proteção possam ser tomadas, bem como as de penalização aos seus agressores.

Quando indagados/as, no grupo focal, se em algum momento da formação acadêmica participaram de discussões sobre o processo histórico da violência contra as mulheres, em consonância com os estudos de gênero, todos/as os/as iniciantes afirmaram que, ainda, não tiveram participação em discussões ligadas às referidas temáticas. Com relação aos/as concluintes, duas falas reverberaram o contato técnico com a Lei Maria da Penha em uma das disciplinas do curso. 
Diante destes achados, se finda este artigo apontando que, a falta de discussões densas sobre a construção social da violência contra as mulheres, na perspectiva dos estudos de gênero, resulta em uma formação técnica desprovida de fundamentação histórico-teórica sobre a temática. Os/as estudantes precisam, também, desconstruir e/ou reelaborar representações instauradas culturalmente em seus processos formativos. Caso contrário, essa formação corroborará com a falta de preparo do/a profissional quando da necessidade de interpretar casos nos quais haja resquícios do patriarcado e do machismo.

\section{REFERÊNCIAS}

BOULOS, Ivete; ROSENTHAL, Caio; DUARTE, Albertina. Debate - Lei Maria da Penha e violência contra a mulher: como atender as mulheres vítimas de violência? Revista ser médico, São Paulo, n. 76, p. 16-22, jul./set. 2016. Disponível em:

https://www.cremesp.org.br/?siteAcao=Revista\&id=861. Acesso em: 27 mai. 2018.

BRABO, Tania Suelly Antonelli Marcelino. Identidade e imagem feminina na escola: o papel do feminismo contra a violência simbólica e outras. In: BRABO, Tania Suelly Antonelli Marcelino. Mulheres Gênero e Violência. Marília: Cultura Acadêmica, 2015. p. 261-272.

BRASIL. Casa Civil. Lei Maria da Penha. Lei no 11.340 de 7 de agosto de 2006. Cria mecanismos para coibir a violência doméstica e familiar contra a mulher, nos termos do § 8ㅇo do art. 226 da Constituição Federal, da Convenção sobre a Eliminação de Todas as Formas de Discriminação contra as Mulheres e da Convenção Interamericana para Prevenir, Punir e Erradicar a Violência contra a Mulher; dispõe sobre a criação dos Juizados de Violência Doméstica e Familiar contra a Mulher; altera o Código de Processo Penal, o Código Penal e a Lei de Execução Penal; e dá outras providências. Planalto, Brasília, DF, 07 ago. 2006. Disponível em:

http://www.planalto.gov.br/ccivil 03/ ato2004-2006/2006/lei/l11340.htm. Acesso em: 13 nov. 2017.

BRASIL. Conselho Nacional de Justiça. Portaria no 15 de 08 de março de 2017. Institui a Política Judiciária Nacional de enfrentamento à violência contra as Mulheres no Poder Judiciário e dá outras providências. CNJ, Brasília, DF, 09 mar. 2017. Disponível em: http://www.cnj.jus.br/files/conteudo/arquivo/2017/03/48676a321d03656e5e3a4f0aa3519e62.pd f. Acesso em: 19 mar. 2018.

CAETANO, Márcio; LIMA, Carlos Henrique Lucas; CASTRO, Amanda Motta. Diversidade sexual, gênero e sexualidades: temas importantes à educação democrática. Colloquium Humanarum, Presidente Prudente-SP, v. 16, n. 3, p. 5-16, nov. 2019. Disponível em:

https://revistas.unoeste.br/index.php/ch/article/view/3179. Acesso em: 25 mai. 2020.

CARDOSO, Adriano Rogério; ZIMMERMANN, Tânia Regina. Gênero e educação, interfaces com grafitos em uma ambiência escolar: possibilidades de pesquisa. Colloquium Humanarum, 
Presidente Prudente-SP, v. 16, n. 3, p. 47-62, nov. 2019. Disponível em:

https://revistas.unoeste.br/index.php/ch/article/view/3151. Acesso em: 25 mai. 2020.

CHAUÍ, Marilena. Ética e violência. Teoria e Debate, São Paulo, n. 39, 1998. Disponível em: https://teoriaedebate.org.br/1998/10/01/etica-e-violencia. Acesso em: 26 nov. 2017.

D'OLIVEIRA, Ana Flávia Pires Lucas; SCHRAIBER, Lilia Blima; FRANÇA-JUNIOR, Ivan; LUDERMIR, Ana Bernarda; PORTELLA, Ana Paula; DINIZ, Carmen Simone; COUTO, Márcia Thereza; VALENÇA, Otávio. Fatores associados à violência por parceiro íntimo em mulheres brasileiras. Revista de

Saúde Pública, São Paulo, v. 43, n. 2, p. 299-310, abr. 2009. DOI 10.1590/S003489102009005000013. Disponível em: https://www.scielo.br/scielo.php?pid=S0034$89102009005000013 \&$ script=sci abstract\&tlng=pt. Acesso em: 19 set. 2017.

ECHEVERRIA, Jasmin Gladys Melcher; OLIVEIRA, Maria Helena Barros; ERTHAL, Regina Maria de Carvalho. Violência doméstica e trabalho: percepções de mulheres assistidas em um Centro de Atendimento à Mulher. Saúde em debate, Rio de Janeiro, v. 41, n. esp. 2, p. 13-24, jun. 2017. DOI 10.1590/0103-11042017s202.Disponível em:

http://www.scielo.br/scielo.php?script=sci arttext\&pid=S0103$11042017000600013 \& \operatorname{lng}=e n \& n r m=i s o$. Acesso em: 19 set. 2017.

FRANCISCO, Marcos Vinicius. A construção social da personalidade de adolescentes expostos ao bullying escolar e os processos de "resiliência em-si": uma análise histórico-cultural. 2013. $266 f$. Tese (Doutorado em Educação), Universidade Estadual Paulista. Presidente Prudente-SP, 2013.

GARBIN, Cléa Adas Saliba; ROVIDA, Tânia Adas Saliba; COSTA, Adriana Alves; GARBIN, Artênio José Isper. Percepção e atitude do cirurgião-dentista servidor público frente à violência intrafamiliar em 24 municípios do interior do estado São Paulo, 2013-2014. Epidemiologia e Serviços de Saúde, Brasília, v. 25, n. 1, p. 179-186, jan./mar. 2016. DOI 10.5123/s1679-49742016000100019. Disponível em: http://www.scielo.br/scielo.php?script=sci arttext\&pid=S223796222016000100179\&lng=en\&nrm=iso. Acesso em: 19 set. 2017.

GARCIA, Leila Posenato. A magnitude invisível da violência contra a mulher. Epidemiologia e Serviços de Saúde, Brasília, v. 25, n. 3, p. 451-454, jul./set., 2016. DOI 10.5123/S167949742016000300001. Disponível em:

http://scielo.iec.gov.br/scielo.php?script=sci arttext\&pid=S167949742016000300451\&lng=pt\&nrm=iso. Acesso em: 19 set. 2017.

GOMES, Nadirlene Pereira; DINIZ, Normélia Maria Freire. Males unveiling the different forms of conjugal violence. Acta paul. enferm., São Paulo , v. 21, n. 2, p. 262-267, 2008. DOI 10.1590/S0103-21002008000200005. Disponível em: http://www.scielo.br/scielo.php?script=sci arttext\&pid=S010321002008000200005\&lng=en\&nrm=iso. Acesso em: 19 set. 2017.

GOMES, Nadirlene Pereira; DINIZ, Normélia Maria Freire; CAMARGO, Climene Laura de; SILVA, Marieve Pereira da. Homens e mulheres em vivência de violência conjugal: características socioeconômicas. Rev. Gaúcha Enferm., Porto Alegre, v. 33, n. 2, p. 109-116, jun. 2012a. DOI 
10.1590/S1983-14472012000200016. Disponível em:

https://www.scielo.br/pdf/rgenf/v33n2/16.pdf Acesso em: 19 set. 2017.

GOMES, Nadirlene Pereira; GARCIA, Talita Castro Santos; CONCEIÇÃO, Clarissa da Rocha; SAMPAIO, Paula de Oliveira; ALMEIDA, Vanessa de Carvalho; PAIXÃO, Gilvânia Patrícia do Nascimento. Violência conjugal: elementos que favorecem o reconhecimento do agravo. Saúde em Debate, Rio de Janeiro, v. 36, n. 95, p. 514-522. out./dez., 2012b. Disponível em: http://www.scielo.br/pdf/sdeb/v36n95/a03v36n95.pdf. Acesso em: 19 set. 2017.

GONDIM, Sônia Maria Guedes. Grupos focais como técnica de investigação qualitativa: desafios metodológicos. Paidéia, Ribeirão Preto, v. 12, n. 24, p. 149-161, 2002. DOI 10.1590/S0103863X2002000300004. Disponível em:

http://www.scielo.br/scielo.php?script=sci arttext\&pid=S0103863X2002000300004\&lng=pt\&nrm=iso. Acesso em: 19 set. 2017.

LEMOS, Marilda de Oliveira. Delegacias de defesa da mulher: o que aconteceu com elas? In: Fazendo Gênero - corpo, violência e poder, 8, 2008, Florianópolis. Anais [...] Florianópolis: UFSC, 2008. Disponível em:

http://www.fazendogenero.ufsc.br/8/sts/ST62/Marilda de Oliveira Lemos 62.pdf. Acesso em: 21 mar. 2018.

LIMA, Milka Oliveira; SOUZA, Ellem Dayanne Rodrigues Vinhal; SILVA, Fábio Araújo. Violência doméstica: evolução do tipo penal. Revista Cereus, Gurupi- TO, v. 9, n. 4, p. 189-205, ago./dez. 2017. Disponível em: http://www.ojs.unirg.edu.br/index.php/1/article/download/1463/592. Acesso em: 19 mar. 2018.

MAROCCO, Andréa de Almeida Leite. Ensino jurídico no Brasil: desafios à formação do profissional do direito no século XXI. 2011. 160 f. Dissertação (Mestrado em Direito) - Universidade Federal de Santa Catarina. Florianópolis, 2011.

MORAES, Aparecida Fonseca; RIBEIRO, Letícia. As políticas de combate à violência contra a mulher no Brasil e a "responsabilização" dos "homens autores de violência". Sexualidad, Salud y

Sociedad, Rio de Janeiro, n. 11, p. 37-58, ago. 2012. Disponível em:

http://www.scielo.br/scielo.php?script=sci arttext\&pid=S1984-

64872012000500003\&lng=en\&nrm=iso. Acesso em: 06 out. 2017.

MORAIS, Adenilda Bertoldo Alves de; CARVALHO, Maria Eulina Pessoa de. Institucionalização dos estudos de gênero na universidade: uma análise a partir de narrativas de acadêmicas feministas. Revista Tempos e Espaços em Educação, São Cristovão-SE, v. 8, n. 17, p. 235-236, 2015. Disponível em: https://seer.ufs.br/index.php/revtee/article/view/4526. Acesso em: 25 mai. 2020.

MINAYO, Maria Cecília Souza. Análise qualitativa: teoria, passos e fidedignidade. Ciência Saúde Coletiva, Rio de Janeiro, v. 17, n. 3, p. 621-626, ago. 2012. Disponível em: http://www.scielo.br/pdf/csc/v17n3/v17n3a07.pdf. Acesso em: 06 out. 2017. 
NARVAZ, Martha Giudice; KOLLER, Silvia Helena. Mulheres vítimas de violência doméstica: compreendendo subjetividade assujeitadas. Psico, Porto Alegre, v. 37, n.1, p 7-13, jan./abr. 2006. Disponível em:

http://revistaseletronicas.pucrs.br/revistapsico/ojs/index.php/revistapsico/article/view/1405/110 5. Acesso em: 19 set. 2017.

OLIVEIRA, Rosane Cristina; LIMA, Jacqueline de Cássia Pinheiro; ARANA, Andressa Maria Freire da Rocha. Da criação das DEAM's à Lei Maria da Penha: uma reflexão sobre a questão da violência contra as mulheres. Revista Cereus Ártemis, João Pessoa, v. 24, n. 1, p. 201-213, jul./dez. 2017. DOI 10.22478/ufpb.1807-8214.2017v24n1.35821. Disponível em:

https://periodicos.ufpb.br/ojs2/index.php/artemis/article/view/35821 Acesso em: 19 mar. 2018.

PADOVANI, Ricardo da Costa; WILLIAMS, Lúcia Calvacanti de Albuquerque. Intervenção psicoterapêutica com agressor conjugal: um estudo de caso. Psicol. Estud, Maringá, v. 7, n. 2, p. 13-17, jul./dez. 2002. DOI 10.1590/S1413-73722002000200003. Disponível em:

http://www.scielo.br/scielo.php?script=sci arttext\&pid=S1413-

73722002000200003\&lng=en\&nrm=iso. Acesso em: 19 jan. 2018.

RIOS, Pedro Paulo Souza; VIEIRA, André Ricardo Lucas. The emerging of a gender discourse in education: the differences in the school space. Revista Tempos e Espaços em Educação, São Cristovão-SE, v. 13, n. 32, p. 1-17, fev. 2020. Disponível em:

https://seer.ufs.br/index.php/revtee/article/view/13061 . Acesso em: 25 mai. 2020.

ROSA, Antonio Gomes da; BOING, Antonio Fernando; BÜCHELE, Fátima; OLIVEIRA, Walter Ferreira; COELHO, Elza Berger Salema. A violência conjugal contra a mulher a partir da ótica do homem autor da violência. Saúde Soc., São Paulo, v. 17, n. 3, p. 152-160, Set. 2008. DOI 10.1590/S010412902008000300015. Disponível em:

http://www.scielo.br/scielo.php?script=sci arttext\&pid=S0104-

$12902008000300015 \&$ Ing=en\&nrm=iso. Acesso em: 19 set. 2017.

ROSA, Larissa Wolff; FALCKE, Denise. Violência conjugal: compreendendo o fenômeno. Revista SPAGESP, Ribeirão Preto, v. 15, n. 1, p. 17-32, mar. 2014. Disponível em: http://pepsic.bvsalud.org/scielo.php?script=sci_arttext\&pid=S1677-29702014000100003. Acesso em: 19 set. 2017.

SANTOS, Ana Claúdia Wendt; MORÉ, Carmen Leontina Ojeda Ocampo. Impacto da Violência no sistema familiar de mulheres vítimas de agressão. Psicologia: Ciência e Profissão, Brasília, v. 31, n. 2, p. 220-235, 2011. DOI 10.1590/S1414-98932011000200003. Disponível em:

http://www.scielo.br/scielo.php?script=sci arttext\&pid=S1414-

98932011000200003\&lng=pt\&nrm=iso

Acesso em: 19 set. 2017.

SCOTT, Joan Wallach. O enigma da igualdade. Estudos Feministas, Florianópolis, v. 13, n. 1, p. 1122, mar/abr. 2005. Disponível em: http://www.scielo.br/pdf/ref/v13n1/a02v13n1.pdf. Acesso em: 19 set. 2017. 
SILVA, Patrick Leonardo Nogueira; ALMEIDA, Sibelle Gonçalves de; MARTINS, Aurelina Gomes; GAMBA, Mônica Antar; ALVES, Elaine Cristina Santos; SILVA JÚNIOR, Renê Ferreira da. Prácticas educativas sobre la violencia contra la mujer en la formación de universitarios. Revista Bioética, Brasília, v. 24, n. 2, p. 276-285 mai./ago., 2016. Disponível em:

http://www.scielo.br/pdf/bioet/v24n2/es 1983-8034-bioet-24-2-0276.pdf. Acesso em: 04 out. 2019.

SOUZA, Edinilsa Ramos de; RIBEIRO, Adalgisa Peixoto; PENNA, Lúcia Helena Garcia; FERREIRA, Ana Lúcia; SANTOS, Neuci Cunha dos; TAVARES, Claudia Mara de Melo. O tema violência intrafamiliar na concepção dos formadores dos profissionais de saúde. Ciência \& Saúde Coletiva, Rio de Janeiro, v. 14, n. 5, p. 1709-1719, nov./dez. 2009. DOI 10.1590/S1413-81232009000500012. Disponível em: http://www.scielo.br/scielo.php?script=sci arttext\&pid=S1413$\underline{81232009000500012 \& \operatorname{lng}=e n \& n r m=i s o}$. Acesso em: 19 set. 2017.

VIDAS Partidas. Direção de Marcos Schechtman. Rio de Janeiro: Globo Filmes, Voglia Produções, 2016. 1 DVD (90 min.).

\section{SOBRE OS AUTORES}

\section{Ricardo Gabriel de Araújo}

Mestre em Educação, Universidade do Oeste Paulista (Unoeste); Universidade do Oeste Paulista/Professor do Curso de Direito; Membro do Grupo de Pesquisa: Estado, Políticas Educacionais e Democracia (EPED). Email: ricardoaraujo@unoeste.br

ORCID: http://orcid.org/0000-0002-8341-5513

\section{Marcos Vinicius Francisco}

Doutor em Educação, Universidade Estadual Paulista (Unesp); Universidade do Oeste Paulista/ Programa de Pós-Graduação em Educação (PPGE/Unoeste); Universidade Estadual de Maringá/Programa de PósGraduação em Educação (PPE/UEM); Líder do Grupo de Pesquisa: Estado, Políticas Educacionais e Democracia (EPED); Investigador do Grupo de Estudos e Pesquisas em Políticas Educacionais, Gestão e Financiamento da Educação (GEPEFI).E-mail: marcos educa01@yahoo.com.br

ORCID: http://orcid.org/0000-0002-5410-2374

\section{Cinthia de Sousa Noguchi}

Mestre em Educação, Universidade do Oeste Paulista (Unoeste); Prefeitura Municipal de Anhumas/Psicóloga; Membro do Grupo de Pesquisa: Estado, Políticas Educacionais e Democracia (EPED). Email: ctnoguchi2@gmail.com

ORCID: http://orcid.org/0000-0002-3493-4659

Recebido em: 27 de março de 2020 Aprovado em: 28 de maio de 2020 Publicado em: 09 de junho de 2020 